\title{
Inhibitory effect of simvastatin in nasopharyngeal carcinoma cells
}

\author{
ZHAOXIN MA*, WEIHUA WANG* ${ }^{*}$ YU ZHANG, MIN YAO, LIYUN YING and LIWEI ZHU \\ Department of Otolaryngology-Head and Neck Surgery, Shanghai East Hospital, \\ Tongji University School of Medicine, Shanghai 200120, P.R. China
}

Received June 6, 2018; Accepted April 16, 2019

DOI: $10.3892 /$ etm.2019.7525

\begin{abstract}
Nasopharyngeal carcinoma (NPC) is one of the most common malignant head and neck cancers in southern China. Although the local and regional control of NPC has been considerably improved, patients with advanced disease still suffer from poor prognosis. Statins inhibit the mevalonate pathway and play antiproliferative and proapoptotic roles in a number of cancer cells. However, the effects and molecular mechanism of statins in NPC treatment remain unclear. In this study, the cell viability of NPC cell line, C666-1, after simvastatin exposure was determined using the alamarBlue Cell Viability Assay. Cell apoptosis in C666-1 treated with simvastatin was assessed by flow cytometry and TUNEL assay. The expression levels of cell cycle regulatory proteins were determined using western blotting. Simvastatin markedly decreased cell viability in a concentration-dependent manner, increased caspase 3 activity and induced apoptosis in C666-1 cells. Simvastatin induced Bim expression by regulating phosphorylation of transcriptional factor c-Jun. Simvastatin treatment induced cell cycle arrest in the G1 phase in C666-1 cells by inhibiting the expression of cyclin D1 and cyclin-dependent kinase 4, and enhancing p27 expression. Simvastatin treatment inhibited protein kinase B and extracellular signal regulated kinase $1 / 2$ activation. In conclusion, the results of the present study reveal the possible molecular mechanism of simvastatin-induced anti-tumor effects in C666-1 and suggest
\end{abstract}

Correspondence to: Professor Zhaoxin Ma, Department of Otolaryngology-Head and Neck Surgery, Shanghai East Hospital, Tongji University School of Medicine, 150 Jimo Road, Shanghai 200120, P.R. China

E-mail: mzhx114@163.com

*Contributed equally

Abbreviations: CDK, cyclin-dependent kinase; CKI, cyclin-dependent kinase inhibitor; HMG-CoA, 3-hydroxy-3methylglutaryl coenzyme A; NPC, nasopharyngeal carcinoma; PI, propidium iodide; TUNEL, terminal deoxynucleotidyl transferase biotin-dUTP nick end labeling

Key words: nasopharyngeal carcinoma, simvastatin, apoptosis, cell cycle, chemotherapy that simvastatin is a potential chemotherapy agent in NPC treatment.

\section{Introduction}

Nasopharyngeal carcinoma (NPC) is the most frequent malignant head and neck cancer in Southeast Asia, especially in southern China. The annual incidence rate is $\sim 20-50$ cases per 100,000 individuals (1). An estimated 42,100 new cases and 21,320 fatalities were attributed to NPC in China in 2013 (2). Epstein-Barr virus infection, genetic factors and environmental conditions are involved in the pathogenesis of NPC (3). A cure rate of $>90 \%$ after radiotherapy has been reported in early stage NPC (4). However, most NPC patients are initially diagnosed as undifferentiated and nonkeratinizing carcinoma at an advanced stage (5).

In recent years, the local and regional control of NPC has been markedly improved with the emergence of intensity-modulated photon-based radiation therapy (6). Although radiotherapy is the primary treatment modality, multidisciplinary management is the current treatment standard, especially for patients with local advanced disease. Concurrent chemotherapy with radiotherapy remains the standard of care (7). At the present time, the 5-year overall survival rate of patients with local advanced NPC is only $50-70 \%$ and $30-40 \%$ of patients still develop distant metastasis within 4 years with $10-20 \%$ developing locoregional relapse (8-10). Patients with advanced disease suffer from a worse outcome. To improve the long-term overall survival rate of NPC, it is crucial to explore more effective treatment modalities.

Statins are 3-hydroxy-3-methylglutaryl coenzyme A (HMG-CoA) reductase inhibitors, which are frequently used as safe and effective therapeutic agents for hypercholesterolemia, contributing to a reduction in morbidity and mortality from atherosclerosis and coronary artery disease $(11,12)$. Statins target mevalonate, one of the cholesterol precursors, which is catalyzed by HMG-CoA reductase. It has been reported that overexpression of mevalonate is associated with cell survival and proliferation of cancer cells (13). Statins inhibit the mevalonate pathway and reduce the synthesis of geranylgeranyl pyrophosphate and farnesyl pyrophosphate, which are indispensable for the posttranslational modification of certain regulatory proteins (14). In addition to a lipid-lowering effect, statins also exert antiproliferative and proapoptotic effects in cancer cells by regulating the cell cycle $(15,16)$. Koul et al (17) demonstrated that inhibition of 
the mevalonate pathway could affect a number of cellular functions in bone-resorbing osteoclasts and inhibit cancer cell proliferation, viability, motility, invasion, and angiogenesis. Statin-induced inhibition of the mevalonate pathway attenuates the growth of mesenchymal-like cancer cells (18). Anticancer effects with in vitro simvastatin treatment have been reported in prostate, breast and ovarian cancer, and adenocarcinoma $(15,19-21)$. However, the effects of simvastatin in NPC remain unclear.

The authors' previous study demonstrated that simvastatin induces loss of cell attachment, reduces colony forming units and inhibits sphere formation in soft gel agar in squamous cell carcinoma of the nasal cavity (22). The results of the present study indicated that statin acts as a relatively safe and cost-effective chemoadjuvant agent in the treatment of nasal malignant tumors. However, little is known about the molecular mechanism of statins in NPC. In the present study, the effect of simvastatin was examined in human NPC cell line, C666-1 and investigated the associated molecular mechanisms.

\section{Materials and methods}

Materials and cell culture. Simvastatin, cisplatin and mevalonic acid lactone were purchased from Sigma-Aldrich (Merck KGaA). For in vitro administration, simvastatin was dissolved in dimethyl sulfoxide (DMSO) at a concentration of $50 \mathrm{mM}$ and stored at $-20^{\circ} \mathrm{C}$ as a stock solution. Mevalonic acid lactone was dissolved in PBS at a concentration of $200 \mathrm{mM}$ as stock solution. C666-1 was purchased from American Type Culture Collection (Thermo Fisher Scientific, Inc.) and cultured in RPMI-1640 (Corning Inc.) supplemented with $10 \%$ fetal bovine serum (FBS; Gibco; Thermo Fisher Scientific, Inc.) and 1\% penicillin/streptomycin (Sigma-Aldrich; Merck KGaA). Cells were cultured at $37^{\circ} \mathrm{C}$ in a humidified atmosphere of $5 \% \mathrm{CO}_{2}$. In the signal pathway experiments, cells were pretreated with JNK inhibitor, SP6000125 (10 $\mu \mathrm{M}$; BioSource; Thermo Fisher Scientific, Inc.), $4 \mathrm{~h}$ before simvastatin treatment.

Cell viability assay. NPC cells were seeded in 96-well plates at a density of $1 \times 10^{4}$ cells per well in $100 \mu \mathrm{l}$ of medium. A total of $24 \mathrm{~h}$ after seeding, cells were treated with the indicated concentrations of simvastatin $(0-100 \mu \mathrm{M})$ for $48 \mathrm{~h}$. Cell viability was determined by alamarBlue Cell Viability Assay according to the manufacturer's protocol (BioSource; Thermo Fisher Scientific, Inc.). Briefly, at the end of incubation, culture supernatant was replaced with alamarBlue reagent $(1: 20 \mathrm{v} / \mathrm{v}$ dilution in fresh culture medium). Plates were incubated at $37^{\circ} \mathrm{C}$ for $2-4 \mathrm{~h}$ and the absorbance was measured at $490 \mathrm{~nm}$ with an Omega microplate reader (Imgen Technologies). Cells were treated with or without $50 \mu \mathrm{M}$ of simvastatin for $48 \mathrm{~h}$, then were observed and photomicrographs were captured using a Leica Microsystems light microscope at a magnification of $\mathrm{x} 400$.

Apoptosis assay. Cell apoptosis was assessed by Annexin $\mathrm{V}$-APC and propidium iodide (PI) assay (BD Biosciences). Briefly, C666-1 cells were treated with or without $50 \mu \mathrm{M}$ of simvastatin for 16 and $24 \mathrm{~h}$. The adherent cells and floating cells were harvested and washed with cold PBS. Cells were resuspended in Annexin binding buffer at a concentration of $5 \times 10^{5}$ cells $/ \mathrm{ml}$ and incubated with Annexin V-APC and PI for $15 \mathrm{~min}$ in the dark at room temperature. After incubation, the cells were analyzed using Acuuri C6 and the data were analyzed using CFlow Plus (Accuri Cytometers).

Caspase 3 fluorimetric assay. C666-1 cells were treated with simvastatin $(50 \mu \mathrm{M})$ or statin plus mevalonate $(200 \mu \mathrm{M})$ for $24 \mathrm{~h}$. After incubation, cells were collected and centrifuged at $300 \mathrm{x} \mathrm{g}$ for $5 \mathrm{~min}$ at $4^{\circ} \mathrm{C}$. A Caspase 3 fluorimetric assay was performed using the Caspase 3 kit (R\&D Systems, Inc., Minneapolis, MN, USA). In brief, pelleted cells were lysed using Lysis Buffer (R\&D Systems, Inc.). A $100 \mu 1$ portion of lysate was transferred into a 96-well plate and mixed with $50 \mu \mathrm{l}$ of Reaction Buffer 3 and $5 \mu \mathrm{l}$ of Caspase-3 fluorogenic substrate. After incubation for $1 \mathrm{~h}$ at $37^{\circ} \mathrm{C}$, caspase activity was determined with an Omega microplate reader.

TUNEL assay. Cells were seeded in 8-well cell culture slides at a density of 500 cells/well. After overnight culture at $37^{\circ} \mathrm{C}$, cells were treated with or without simvastatin $(50 \mu \mathrm{M})$ or simvastatin plus cisplatin $(35 \mu \mathrm{M})$ for $24 \mathrm{~h}$ and the TUNEL assay was performed (R\&D Systems, Inc.). The treated cells were labeled using terminal deoxynucleotidyl transferase to transfer biotin-dUTP to the free 3'-OH of cleaved DNA at $37^{\circ} \mathrm{C}$ for $1 \mathrm{~h}$. Then the slides were incubated in the dark with avidin-fluorescein isothiocyanate for $20 \mathrm{~min}$ at room temperature and 3 fields were visualized by fluorescence microscopy at a magnification of $\mathrm{x} 400$.

Western blot analysis. Total protein was extracted from C666-1 cells using radioimmunoprecipitation assay (RIPA) buffer (Sigma-Aldrich; Merck KGaA) and protein concentrations were quantified with the bicinchoninic acid Protein Assay kit (Beyotime Institute of Biotechnology, Haimen, China). Samples (10-30 $\mu \mathrm{g}$ ) were separated by $10 \%$ SDS-PAGE and transferred to nitrocellulose membranes (EMD Millipore, Billerica, MA, USA). The membranes were blocked with $5 \%$ nonfat milk in TBS-T for $1 \mathrm{~h}$ at room temperature and then incubated overnight at $4^{\circ} \mathrm{C}$ with the following primary antibodies $(1: 1,000)$ : Polyclonal rabbit anti cleaved Caspase-3 (cat. no. 9661), polyclonal rabbit anti Bim (cat. no. 2819), polyclonal rabbit anti Bax (cat. no. 2772), monoclonal rabbit anti phosphorylated protein kinase B (p-Akt; cat. no. 4058), polyclonal rabbit anti Akt (cat. no. 9272), monoclonal rabbit anti p-extracellular signal regulated kinase (Erk)1/2 (cat. no. 9106), polyclonal rabbit anti Erk1/2 (cat. no. 9102) and c-Jun (all from Cell Signaling Technology, Inc., Danvers, MA, USA), monoclonal rabbit anti p-c-Jun (cat. no. 1527; Epitomics, Abcam, Cambridge, UK), polyclonal rabbit anti $\alpha$ tubulin (cat. no. sc-5546), polyclonal rabbit anti p27 (cat. no. sc-528), polyclonal rabbit anti cyclin-dependent kinase (CDK4; cat. no. sc-260), and monoclonal mouse anti cyclin D1 (cat. no. sc-246; Santa Cruz Biotechnology, Inc., Dallas, TX, USA). After washing, membranes were further incubated with secondary antibodies (anti rabbit: sc-2004 and anti-mouse: sc-2005, both from Santa Cruz Biotechnology, Inc.; 1:5,000) conjugated with horseradish peroxidase for $1 \mathrm{~h}$ at room temperature. The immunoreactive signal was detected using the enhanced 
A

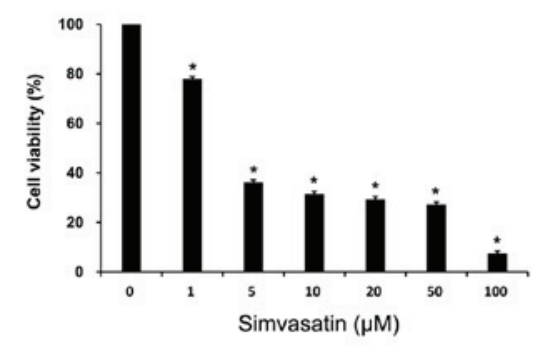

C

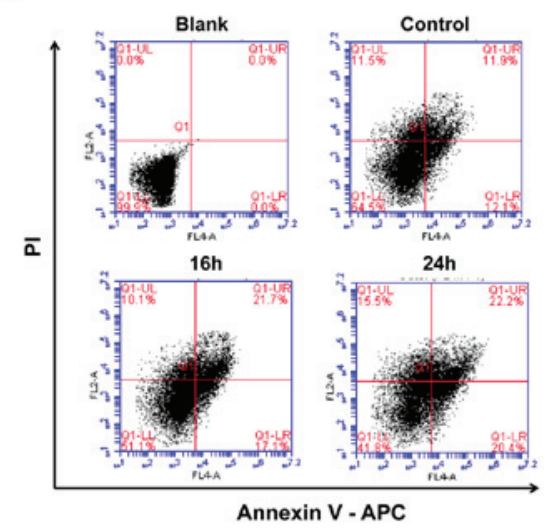

$\mathrm{F}$

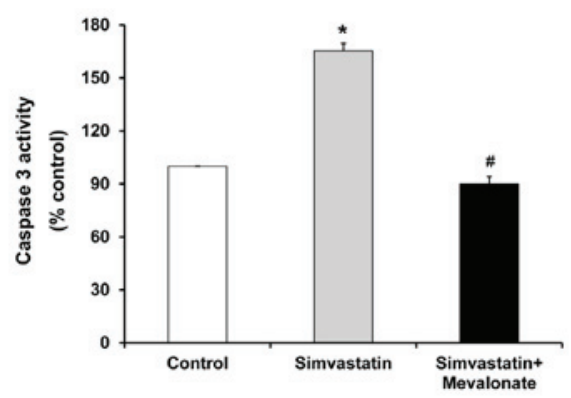

B

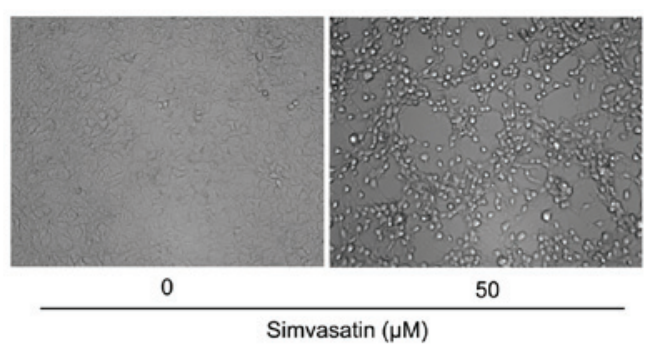

D

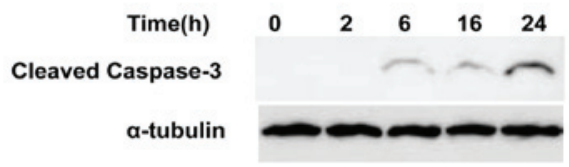

$E$

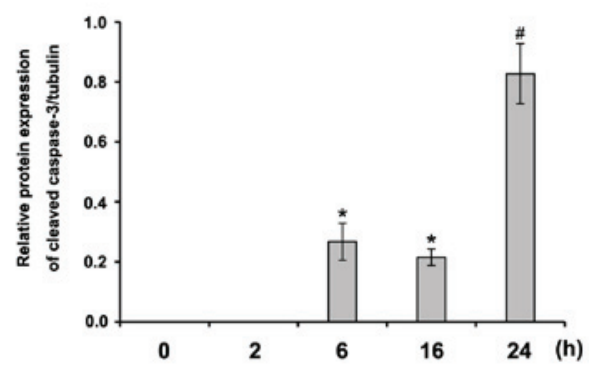

Figure 1. Simvastatin inhibits cell viability and promotes apoptosis in C666-1 cells. (A) C666-1 cells were treated with increasing concentrations of simvastatin for $48 \mathrm{~h}$ and cell viability was measured using the alamarBlue Assay. The viability of the control cells was set as $100 \%$ and the viability relative to the control cells is presented. Experiments were performed three times in triplicate. ${ }^{*} \mathrm{P}<0.05$ vs. the control cells. (B) Images of C666-1 cells were captures at a magnification of $\mathrm{x} 400$ after $48 \mathrm{~h}$ of treatment with or without simvastatin $(50 \mu \mathrm{M})$. (C) Determination of apoptotic cells by Annexin V assay. Cells were treated with or without $50 \mu \mathrm{M}$ of simvastatin for the indicated times. Cells were analyzed by flow cytometry. The data represent one of three experiments. (D) Activation of Caspase 3 by simvastatin treatment. Immunoblotting demonstrated that caspase 3 was gradually cleaved in C666-1 cells within $24 \mathrm{~h}$ after simvastatin $(50 \mu \mathrm{M})$ treatment. Immunoblots are representative of three independent experiments. (E) Quantified expression of cleaved caspase 3 protein. Data are presented as mean \pm standard deviation $(\mathrm{n}=3)$. ${ }^{\mathrm{P}} \mathrm{P}<0.05$ vs. the control cells; ${ }^{~} \mathrm{P}<0.05$ vs. the simvastatin-treated cells for $0,2,6$ and 16 h. (F) Fluorimetric assay of caspase 3 activity. Cells were treated with or without $50 \mu \mathrm{M}$ of simvastatin in the presence or absence of mevalonate $(200 \mu \mathrm{M})$ for 24 h. Caspase 3 activity was determined using a microplate reader. Experiments were performed three times in triplicate. ${ }^{*} \mathrm{P}<0.05$ vs. the control cells; ${ }^{*} \mathrm{P}<0.05$ vs. the simvastatin-treated cells.

chemiluminescent detection system (GE Healthcare, Piscataway, NJ, USA).

Cell cycle analysis. After treatment with simvastatin, cell cycle distribution and ploidy status of C666-1 cells were determined by flow cytometry. Cells were collected and washed in PBS, then fixed with $70 \%$ ice-cold ethanol for $24 \mathrm{~h}$ at $-20^{\circ} \mathrm{C}$. The fixed cells were treated with $10 \mathrm{mg} / \mathrm{ml}$ RNAse for $30 \mathrm{~min}$ at $37^{\circ} \mathrm{C}$. The DNA content of cells was evaluated by CFlow after staining with PI $(50 \mu \mathrm{g} / \mathrm{ml})$.

Statistical analysis. Results were expressed as the mean \pm standard deviation. Statistical analysis was performed by Student's t-test or analysis of variance using SPSS version 19 (IBM, Corp., Armonk, NY, USA). SNK-q was used for comparisons among groups. $\mathrm{P}<0.05$ was considered to be a statistically significant difference.

\section{Results}

Effect of simvastatin on the viability of C666-1 cells. To determine the inhibitory effect of simvastatin on C666-1 cell viability, the alamarBlue Cell Viability Assay was performed. C666-1 cells were treated with various concentrations of simvastatin for $48 \mathrm{~h}$ and cell viability was measured. As presented in Fig. 1A, simvastatin statistically significantly decreased cell viability in a 
A

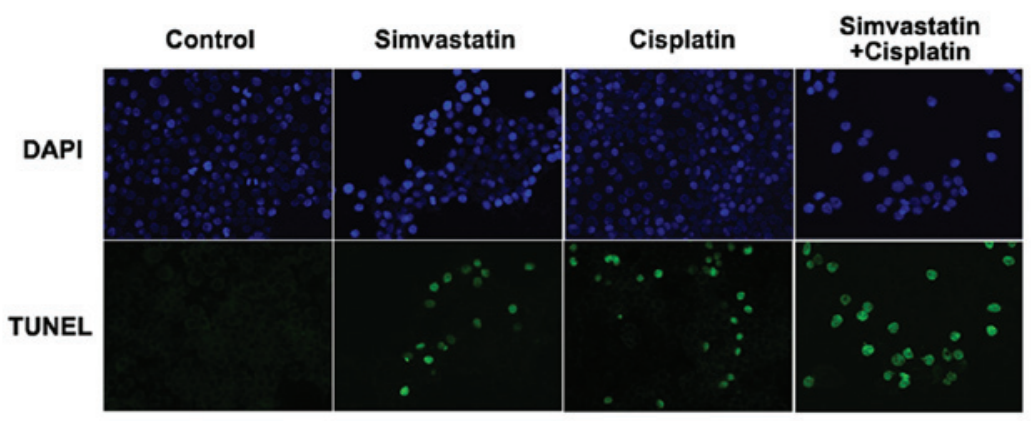

B

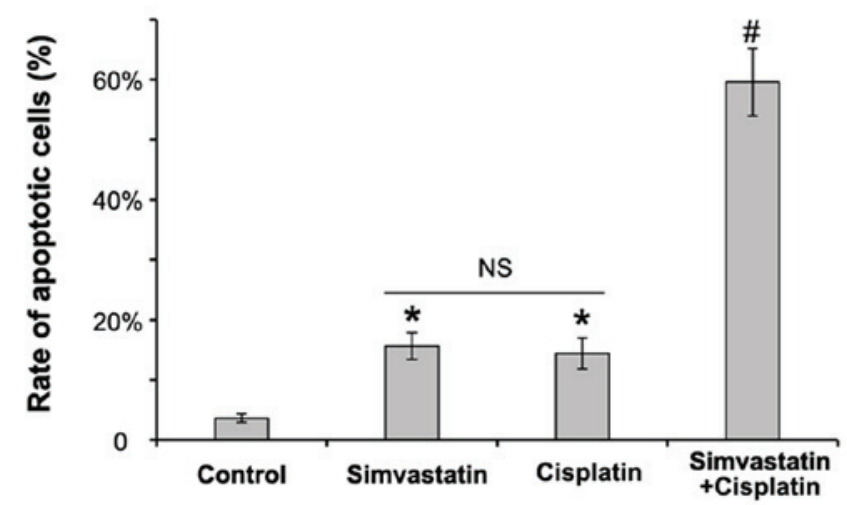

Figure 2. Simvastatin enhances the anti-tumor effect of cisplatin in C666-1 cells. C666-1 cells were treated with simvastatin (50 $\mu \mathrm{M})$ or cisplatin ( $35 \mu \mathrm{M})$ alone or a combination of both for $24 \mathrm{~h}$. Apoptosis was subjected to TUNEL assay. (A) Fluorescence photomicrographs of culture slides were captured at a magnification of $\mathrm{x} 400$ by fluorescence microscopy. Images are representative of three independent experiments. (B) Rate of apoptosis of C666-1 cells. Data are presented as mean \pm standard deviation $(\mathrm{n}=3)$. ${ }^{*} \mathrm{P}<0.05$ vs. the control cells; ${ }^{*} \mathrm{P}<0.05$ vs. the simvastatin or cisplatin-treated cells; NS, no statistically significant difference.

concentration-dependent manner over the dose range of 1-100 $\mu \mathrm{M}$ $(\mathrm{P}<0.05)$. Cell morphology was changed and the number of adherent cells was reduced after statin treatment (Fig. 1B).

Effect of simvastatin on apoptosis and caspase 3 activity in C666-1 cells. To examine whether the decreased viability of C666-1 is due to statin-induced apoptosis, cell apoptosis in C666-1 was evaluated using flow cytometry. C666-1 cells treated with $50 \mu \mathrm{M}$ of simvastatin for up to $24 \mathrm{~h}$ were subjected to Annexin V assay. Statin treatment increased the proportion of apoptotic cells in the early (Annexin $\mathrm{V}^{+} / \mathrm{PI}^{-}$: From $12.6 \pm 0.8$ to $19.5 \pm 1.8 \%$ ) and late (Annexin $\mathrm{V}^{+} / \mathrm{PI}^{+}$: From $12.3 \pm 1.0$ to $21.3 \pm 2.1 \%$ ) stages (Fig. 1C). To further elucidate the statin-induced apoptosis in NPC, the effect of simvastatin exposure on caspase 3 activity in C666-1 cells was evaluated. Simvastatin statistically significantly increased the expression of cleaved caspase 3 after 6 h exposure ( $P<0.05$; Fig. 1D and $\mathrm{E})$ and induced caspase 3 activity by a 1.6 -fold increase in C666-1 cells compared with untreated cells $(\mathrm{P}<0.05$; Fig. $1 \mathrm{~F})$. Interestingly, supplementation of mevalonate, one of the HMG-CoA reductase downstream products, significantly reversed the increased caspase 3 activation induced by simvastatin $(\mathrm{P}<0.01$; Fig. $1 \mathrm{~F})$. These results indicate that cell apoptosis induced by simvastatin in C666-1 cells is mediated through the HMG-CoA reductase pathway.
Simvastatin enhances the anti-tumor effects of cisplatin in C666-1 cells. Combination chemotherapy is an ideal therapeutic approach recommended in most cancers. An experiment was designed using cisplatin and simvastatin to assess the inhibitory effects of statin in C666-1 cells. Cells were treated with simvastatin $(50 \mu \mathrm{M})$ or cisplatin $(35 \mu \mathrm{M})$ alone, or a combination of the two, for $24 \mathrm{~h}$. Cell apoptosis was assessed by TUNEL assay. As presented in Fig. 2, treatment with a combination of cisplatin and simvastatin statistically significantly induced apoptosis in C666-1 cells compared with those treated with simvastatin or cisplatin alone $(\mathrm{P}<0.01)$. This result confirms that simvastatin has a synergistic antitumor effect with a conventional agent in NPC.

Simvastatin induces Bim expression by activating the JNK pathway in C666-1 cells. There are two major apoptotic pathways, the mitochondrial and death receptor pathways. The Bcl-2 family, members of the mitochondrial apoptosis pathway, can induce antiapoptotic and proapoptotic effects. To clarify whether the Bcl-2 family plays a role in statin-induced apoptosis in C666-1 cells, the expression of two proapoptotic members, Bim and Bax was observed. Simvastatin induced the expression of Bim (Fig. 3A and B), but not Bax (Fig. 3A and C), in a time-dependent manner, suggesting that statin may induce C666-1 cell apoptosis through the mitochondrial apoptotic 
A

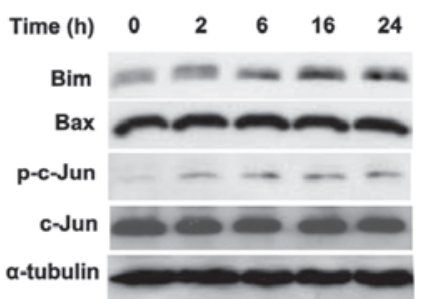

B

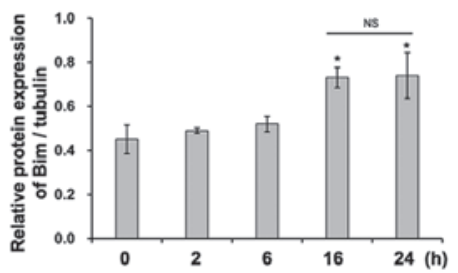

C

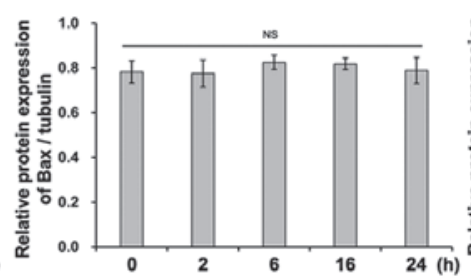

D

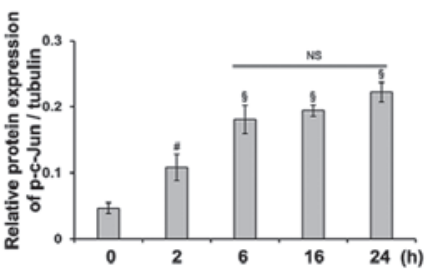

E

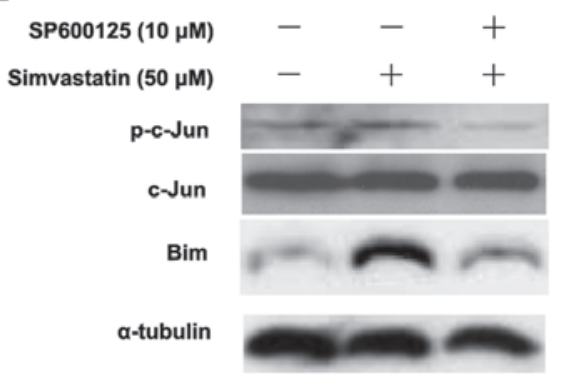

F

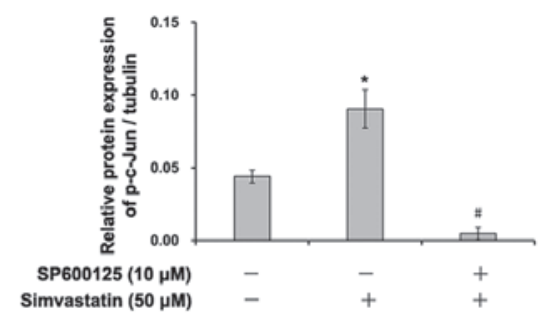

G

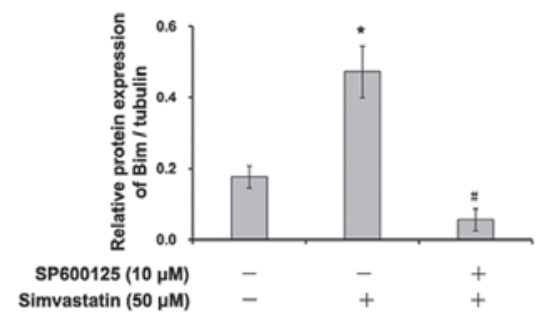

Figure 3. Simvastatin induces Bim expression by activating the JNK pathway in C666-1 cells. (A) C666-1 cells were treated with or without $50 \mu \mathrm{M}$ of simvastatin for the indicated times and the protein expression was assessed by western blotting with the indicated antibodies. Immunoblots are representative of three independent experiments. Quantified expression of (B) Bim, (C) Bax and (D) p-c-Jun protein. Data are presented as mean \pm standard deviation ( $\mathrm{n}=3$ ). ${ }^{*} \mathrm{P}<0.05$ vs. the simvastatin-treated cells for 0,2 , and $6 \mathrm{~h} ;{ }^{*} \mathrm{P}<0.05$ vs. the simvastatin-untreated cells; ${ }^{\circledR} \mathrm{P}<0.05$ vs. the simvastatin-treated cells for 0 and $2 \mathrm{~h}$. (E) Cells were treated with the vehicle or $50 \mu \mathrm{M}$ of simvastatin with or without the pretreatment of SP600125 for $24 \mathrm{~h}$. The expression of Bim, phosphorylated c-Jun, and c-Jun were analyzed by western blotting. Immunoblots are representative of three independent experiments. Quantified expression of (F) p-c-Jun and (G) Bim protein. Data are presented as mean \pm standard deviation $(n=3) .{ }^{*} \mathrm{P}<0.05$ vs. the control cells; ${ }^{*} \mathrm{P}<0.05$ vs. the simvastatin-treated cells. NS, not significant; $\mathrm{p}$, phosphorylated.

Table I. Cell cycle distribution induced by simvastatin in C666-1 cells.

\begin{tabular}{lcc}
\hline & Control $(\%)$ & Simvastatin $(50 \mu \mathrm{M})(\%)$ \\
\hline G1 & $53.90 \pm 3.33$ & $76.40 \pm 3.65^{\mathrm{a}}$ \\
$\mathrm{S}$ & $24.83 \pm 2.83$ & $9.37 \pm 2.02^{\mathrm{a}}$ \\
$\mathrm{G} 2 / \mathrm{M}$ & $12.90 \pm 1.93$ & $12.87 \pm 1.83$ \\
\hline
\end{tabular}

Values are the mean \pm standard deviation. ${ }^{\mathrm{a}} \mathrm{P}<0.05$ vs. control cells.

pathway. Meanwhile, increased expression of phosphorylated c-Jun in C666-1 cells was observed after simvastatin treatment (Fig. 3A and D). As is already known, the JNK pathway plays an important role in regulating phosphorylation of transcriptional factor c-Jun. Then, C666-1 cells were pretreated with a JNK inhibitor, SP6000125, before exposing them to simvastatin. The expression of Bim (Fig. 3E and G) and phosphorylated c-Jun (Fig. 3E and F) was significantly decreased by SP6000125 pretreatment $(\mathrm{P}<0.05)$. These results indicate that the JNK pathway may be involved in statin-induced apoptosis in C666-1 cells.

Effect of simvastatin on cell cycle progress in C666-1 cells. To evaluate the effect of statin on cell cycle, C666-1 cells were incubated with $50 \mu \mathrm{M}$ of simvastatin for up to $48 \mathrm{~h}$. The statin induced a decrease in the total S- and G2/M-phase population in C666-1 cells (Fig. 4A and Table I). The statin-induced inhibition of S- and G2/M-phases appeared to be associated with a simultaneously increasing proportion of
G1 phase, suggesting that simvastatin probably induced G1 arrest in C666-1 cells.

Effects of simvastatin on the activation of mitogen-activated protein kinase 1 (MAPK) and Akt and the expression of cell cycle regulatory proteins. The present study sought to identify the molecular mechanism involved in statin-induced inhibitory effects in C666-1 cells. Western blot analysis demonstrated that the phosphorylated levels of Akt and Erk1/2 were downregulated by simvastatin (Fig. 4B-D). As described above, statin treatment induced cell cycle arrest in the G1 phase. Therefore, the effects of simvastatin on the expression of cell cycle regulatory proteins was examined. The results of the present study demonstrated that simvastatin induced a markedly increase in p27 expression (Fig. 4E and $\mathrm{H}$ ) and decreased the expression of cyclin D1 (Fig. 4E and F) and CDK 4 (Fig. 4E and G) in $\mathrm{C666-1}$ cells. Interestingly, mevalonate partially reversed these effects induced by statin.

\section{Discussion}

The results of the present study demonstrated that simvastatin decreased cell viability in C666-1 cells and the statin-induced inhibitory effects were associated with HMG-CoA reductase-dependent apoptosis and cell cycle arrest. It was demonstrated that simvastatin has a synergistic anti-tumor effect with cisplatin in NPC cells and suggest the potential utility of statins as a chemopreventive agent in the treatment of NPC.

Simvastatin induces apoptosis in NPC cells through the mitochondrial apoptotic pathway. There are a variety of molecules involved in apoptosis. A well-known group of these 
A

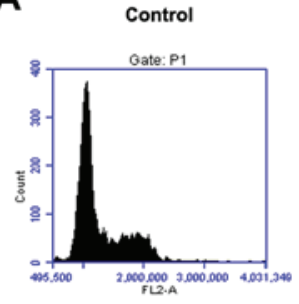

B

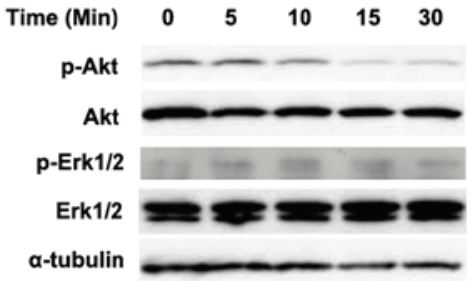

E

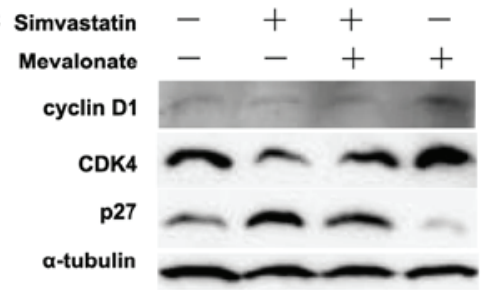

H

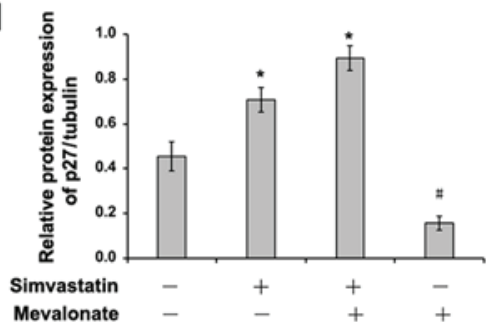

Simvastatin $(50 \mu \mathrm{M})$
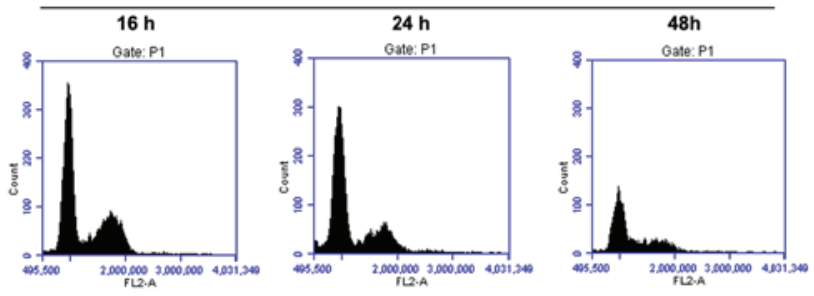

C

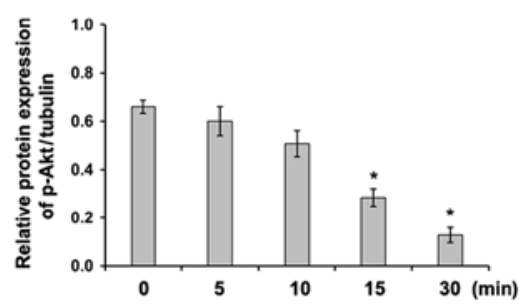

F

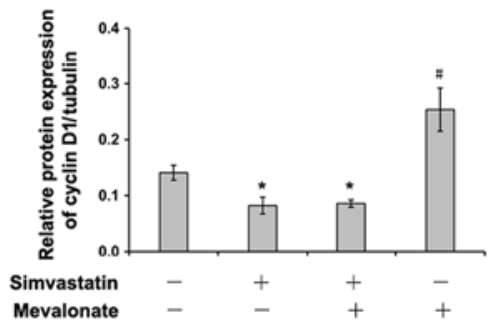

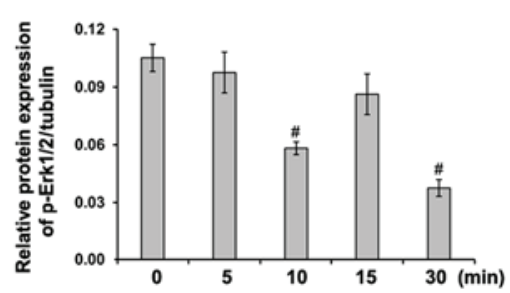

G

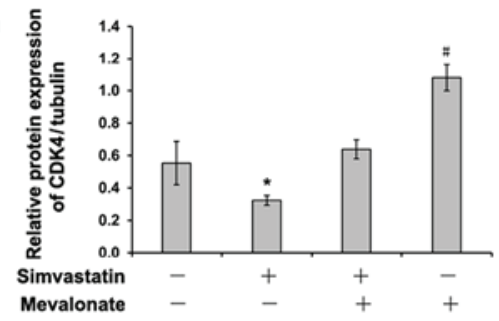

Figure 4. Simvastatin regulates cell cycle distribution and phosphorylation of Akt and Erk1/2 in C666-1 cells. (A) C666-1 cells were treated with or without $50 \mu \mathrm{M}$ of simvastatin for the indicated times and subjected to DNA analysis by flow cytometry. The data represent one of three experiments. (B) The expression of p-Akt, p-Erk1/2, Akt and Erk1/2 were determined by western blotting. Quantified expression of (C) p-Akt and (D) p-Erk1/2 protein. Data are presented as the mean \pm standard deviation $(\mathrm{n}=3)$. ${ }^{*} \mathrm{P}<0.05$ vs. the simvastatin-treated cells for 0,5 and $10 \mathrm{~min} ;{ }^{*} \mathrm{P}<0.05$ vs. the simvastatin-treated cells for 0,5 and $15 \mathrm{~min}$. (E) C666-1 cells were treated with or without $50 \mu \mathrm{M}$ of simvastatin in the presence or absence of $200 \mu \mathrm{M}$ of mevalonate for $24 \mathrm{~h}$. The expression of cyclin D1, CDK4 and p27 was determined by western blotting. Quantified expression of (F) cyclin D1, (G) CDK4 and (H) p27 protein. Data are presented as the mean \pm standard deviation $(n=3) .{ }^{~} \mathrm{P}<0.05$ vs. the control cells; ${ }^{*} \mathrm{P}<0.05$ vs. the simvastatin-treated or simvastatin- and mevalonate-treated cells. $\mathrm{P}-\mathrm{Akt}$, phosphorylated protein kinase B; Erk, extracellular signal regulated kinase; CDK, cyclin-dependent kinase; NS, not significant.

molecules is the Bcl-2 family, which is the important member of the mitochondrial apoptotic pathway. The proapoptotic Bcl-2 family members induce cell death by translocating from the mitochondrial membrane to cytosol (23). Signaling via the JNK pathway has been linked to altered expression of Bcl-2 family members in ovarian cancer and melanoma $(19,24)$. The results of the present study demonstrated that Bim, but not Bax, a proapoptotic Bcl-2 family member, was induced in NPC cells after simvastatin treatment. Bim initiates mitochondrial dysfunction and activates the mitochondrial apoptotic pathway by releasing cytochrome $c$ and activating Caspase 3 . Transcription factor c-Jun regulates Bim expression in neurons by nerve growth factor (25). The result of the present study is consistent with a previous study (19). An increase in the levels of active, cleaved Caspase-3 and phosphorylated c-Jun in C666-1 cells was observed after simvastatin treatment, suggesting that simvastatin promotes apoptosis in C666-1 cells by inducing Bim expression.
Statin-induced cell cycle arrest in G1 probably results from decreased expression of cyclin D1 and a corresponding increase in p27. The present study's DNA ploidy analysis revealed that the treatment of C666-1 cells with simvastatin resulted in cell cycle arrest in the G1 phase. Mitogenic stimuli may increase the intracellular level of cyclin D1, which then forms an complex with CDK4 and 6. Active cyclin D1-CDK4/6 complexes sequentially phosphorylate and inactivate the retinoblastoma $(\mathrm{Rb})$ protein to initiate $\mathrm{E} 2 \mathrm{~F}$-dependent transcription, a requirement for cell cycle progression into the S-phase (26,27). Exogenous cyclin D1 has been demonstrated to increase cyclin D1/CDK4 activity and cause hyperphosphorylation of the $\mathrm{Rb}$ protein. Inhibition of cyclin D1 activation with siRNA results in a significant reduction in $\mathrm{Rb}$ hyperphosphorylation and is associated with G1 cell cycle arrest in breast cancer cells $(15,28)$. Suppression of cyclin D1 activity has been demonstrated to significantly reduce mammary tumorigenesis (29). In the present study, simvastatin 
decreased the expression of cyclin D1 and CDK4 in C666-1 cells. Notably, statin treatment induced an increase in the expression of one of the CDK inhibitors, p27. Wali et al (30), demonstrated that statins promoted p27 upregulation via promoter activation in mammary tumors. The present study provides the first evidence that simvastatin also increases the expression of a CDK inhibitor in NPC cells. Upregulation of p27 induced by statins is significantly associated with overcoming anoikis resistance in head and neck squamous cell carcinoma cells (16). P27 could be a potential target for the anticancer effect of statins in NPC.

Statins can inhibit phosphorylation and activation of Akt and MAPK mitogenic signaling in mammary tumor cells (31). It has been reported that activation of these pathways simulated cell cycle progression from $\mathrm{G} 1$ to $\mathrm{S}$ phase through activating cyclin D1 (26,32). Activation of Akt can enhance cyclin D1 transcription and protein expression, phosphorylate glycogen synthase kinase $3 \beta$ (GSK3 $\beta$ ), and thereby prevent GSK3 $\beta$ from phosphorylating and destabilizing cyclin D1 protein $(26,33)$. In addition, FOXO transcription factors, which inhibit cyclin D1 expression and induce p27 expression, are also phosphorylated and inhibited by Akt pathway activation (34). Similarly, MAPK activation results in phosphorylation and stabilization of c-myc, which induces cyclin D1 and inhibits CKI expression $(35,36)$. Taken together, the results of the present study indicate that statin-induced changes in endogenous cyclin and CDK could result from the inhibition of Akt and Erk1/2 in C666-1 cells.

In conclusion, in this study, it was demonstrated that simvastatin induced apoptosis by upregulating Bim expression and arrested the cell cycle in the G1 phase by decreasing the expression of cyclin D1 and CDK4, and increasing p27 expression in C666-1 cells. Treatment with simvastatin inhibited Akt and Erk1/2 activation. Mitogenic signaling can regulate cell cycle progression by activating cyclin D1 and CDK4, while inhibiting p27 expression. The results of the present study indicate that simvastatin is a potential chemotherapy agent in NPC treatment.

\section{Acknowledgements}

Not applicable.

\section{Funding}

The present study was supported by the National Natural Science Foundation of China (grant no. 81300809) and the Shanghai Pudong New Area Science \& Technology Development Fund (grant nos. PKJ2016-Y02 and PW2016D-11).

\section{Availability of data and materials}

The datasets for this study are available from the corresponding authors on reasonable request.

\section{Authors' contributions}

YZ, MY, LY and LZ performed the experiments, and carried out the data analysis. ZM and WW were responsible for manuscript writing and revision, and experimental design.

\section{Ethics approval and consent to participate}

Not applicable.

\section{Patient consent for publication}

Not applicable.

\section{Competing interests}

The authors declare that they have no competing interests.

\section{References}

1. Jemal A, Bray F, Center MM, Ferlay J, Ward E and Forman D: Global cancer statistics. CA Cancer J Clin 61: 69-90, 2011.

2. Wei KR, Zheng RS, Zhang SW, Liang ZH, Li ZM and Chen WQ: Nasopharyngeal carcinoma incidence and mortality in China, 2013. Chin J Cancer 36: 90, 2017.

3. Nor Hashim NA, Ramzi NH, Velapasamy S, Alex L, Chahil JK, Lye SH, Munretnam K, Haron MR and Ler LW: Identification of genetic and non-genetic risk factors for nasopharyngeal carcinoma in a Southeast Asian population. Asian Pac J Cancer Prev 13: 6005-6010, 2012.

4. Chua DT, Sham JS, Kwong DL and Au GK: Treatment outcome after radiotherapy alone for patients with Stage I-II nasopharyngeal carcinoma. Cancer 98: 74-80, 2003.

5. Yau TK, Lee AW, Wong DH, Pang ES, Ng WT, Yeung RM and Soong IS: Treatment of Stage IV(A-B) nasopharyngeal carcinoma by induction-concurrent chemoradiotherapy and accelerated fractionation: Impact of chemotherapy schemes. Int J Radiat Oncol Biol Phys 66: 1004-1010, 2006.

6. Qiu S, Lin S, Tham IW, Pan J,Lu J and Lu JJ: Intensity-modulated radiation therapy in the salvage of locally recurrent nasopharyngeal carcinoma. Int J Radiat Oncol Biol Phys 83: 676-683, 2012.

7. Chua MLK, Wee JTS, Hui EP and Chan ATC: Nasopharyngeal carcinoma. Lancet 387: 1012-1024, 2016.

8. Ng WT, Lee MC, Hung WM, Choi CW, Lee KC, Chan OS and Lee AW: Clinical outcomes and patterns of failure after intensity-modulated radiotherapy for nasopharyngeal carcinoma. Int J Radiat Oncol Biol Phys 79: 420-428, 2011.

9. Ou X, Zhou X, Shi Q, Xing X, Yang Y, Xu T, Shen C, Wang X, He X, Kong L, et al: Treatment outcomes and late toxicities of 869 patients with nasopharyngeal carcinoma treated with definitive intensity modulated radiation therapy: New insight into the value of total dose of cisplatin and radiation boost. Oncotarget 6: 38381-38397, 2015.

10. Sun X, Su S, Chen C, Han F, Zhao C, Xiao W, Deng X, Huang S, Lin C and Lu T: Long-term outcomes of intensity-modulated radiotherapy for 868 patients with nasopharyngeal carcinoma: An analysis of survival and treatment toxicities. Radiother Oncol 110: 398-403, 2014.

11. Causevic-Ramosevac A and Semiz S: Drug interactions with statins. Acta Pharm 63: 277-293, 2013.

12. Reiner Z: Resistance and intolerance to statins. Nutr Metab Cardiovasc Dis 24: 1057-1066, 2014.

13. Duncan RE, El-Sohemy A and Archer MC: Mevalonate promotes the growth of tumors derived from human cancer cells in vivo and stimulates proliferation in vitro with enhanced cyclin-dependent kinase-2 activity. J Biol Chem 279: 33079-33084, 2004.

14. Bockorny B and Dasanu CA: HMG-CoA reductase inhibitors as adjuvant treatment for hematologic malignancies: What is the current evidence? Ann Hematol 94: 1-12, 2015.

15. Feldt M, Bjarnadottir O, Kimbung S, Jirström K, Bendahl PO, Veerla S, Grabau D, Hedenfalk I and Borgquist S: Statin-induced anti-proliferative effects via cyclin D1 and p27 in a window-of-opportunity breast cancer trial. J Transl Med 13: 133, 2015.

16. Takeda I, Maruya S, Shirasaki T, Mizukami H, Takahata T, Myers JN, Kakehata S, Yagihashi S and Shinkawa H: Simvastatin inactivates beta1-integrin and extracellular signal-related kinase signaling and inhibits cell proliferation in head and neck squamous cell carcinoma cells. Cancer Sci 98: 890-899, 2007. 
17. Koul HK, Koul S and Meacham RB: New role for an established drug? Bisphosphonates as potential anticancer agents. Prostate Cancer Prostatic Dis 15: 111-119, 2012.

18. Warita K, Warita T, Beckwitt CH, Schurdak ME, Vazquez A, Wells A and Oltvai ZN: Statin-induced mevalonate pathway inhibition attenuates the growth of mesenchymal-like cancer cells that lack functional E-cadherin mediated cell cohesion. Sci Rep 4: 7593, 2014

19. Liu H, Liang SL, Kumar S, Weyman CM, Liu W and Zhou A: Statins induce apoptosis in ovarian cancer cells through activation of JNK and enhancement of Bim expression. Cancer Chemother Pharmacol 63: 997-1005, 2009.

20. Parikh A, Childress C, Deitrick K, Lin Q, Rukstalis D and Yang W: Statin-induced autophagy by inhibition of geranylgeranyl biosynthesis in prostate cancer PC3 cells. Prostate 70: 971-981, 2010.

21. Ogunwobi $\mathrm{OO}$ and Beales IL: Statins inhibit proliferation and induce apoptosis in Barrett's esophageal adenocarcinoma cells. Am J Gastroenterol 103: 825-837, 2008.

22. Wang W, Le W, Cho DY, Hwang PH and Upadhyay D: Novel effects of statins in enhancing efficacy of chemotherapy in vitro in nasopharyngeal carcinoma. Int Forum Allergy Rhinol 1: 284-289, 2011.

23. Hiura TS, Li N, Kaplan R, Horwitz M, Seagrave JC and Nel AE: The role of a mitochondrial pathway in the induction of apoptosis by chemicals extracted from diesel exhaust particles. J Immunol 165: 2703-2711, 2000.

24. Zhu BK, Wang $\mathrm{P}$, Zhang XD, Jiang CC, Chen LH, Avery-Kiejda KA, Watts R and Hersey P: Activation of Jun $\mathrm{N}$-terminal kinase is a mediator of vincristine-induced apoptosis of melanoma cells. Anticancer Drugs 19: 189-200, 2008.

25. Biswas SC, Shi Y, Sproul A and Greene LA: Pro-apoptotic Bim induction in response to nerve growth factor deprivation requires simultaneous activation of three different death signaling pathways. J Biol Chem 282: 29368-29374, 2007.

26. Massague J: G1 cell-cycle control and cancer. Nature 432: 298-306, 2004

27. Musgrove EA, Lee CS, Buckley MF and Sutherland RL: Cyclin D1 induction in breast cancer cells shortens G1 and is sufficient for cells arrested in G1 to complete the cell cycle. Proc Natl Acad Sci USA 91: 8022-8026, 1994
28. Grillo M, Bott MJ, Khandke N, McGinnis JP, Miranda M, Meyyappan M, Rosfjord EC and Rabindran SK: Validation of cyclin D1/CDK4 as an anticancer drug target in MCF-7 breast cancer cells: Effect of regulated overexpression of cyclin D1 and siRNA-mediated inhibition of endogenous cyclin D1 and CDK4 expression. Breast Cancer Res Treat 95: 185-194, 2006.

29. Arber N, Doki Y, Han EK, Sgambato A, Zhou P, Kim NH, Delohery T, Klein MG, Holt PR and Weinstein IB: Antisense to cyclin D1 inhibits the growth and tumorigenicity of human colon cancer cells. Cancer Res 57: 1569-1574, 1997.

30. Wali VB, Bachawal SV and Sylvester PW: Combined treatment of gamma-tocotrienol with statins induce mammary tumor cell cycle arrest in G1. Exp Biol Med (Maywood) 234: 639-650, 2009.

31. Wali VB and Sylvester PW: Synergistic antiproliferative effects of gamma-tocotrienol and statin treatment on mammary tumor cells. Lipids 42: 1113-1123, 2007.

32. Torii S, Yamamoto T, Tsuchiya Y and Nishida E: ERK MAP kinase in G cell cycle progression and cancer. Cancer Sci 97: 697-702, 2006.

33. Liang J and Slingerland JM: Multiple roles of the PI3K/PKB (Akt) pathway in cell cycle progression. Cell Cycle 2: 339-345, 2003.

34. Tran H, Brunet A, Griffith EC and Greenberg ME: The many forks in FOXO's road. Sci STKE 2003: RE5, 2003.

35. Reagan-Shaw S, Afaq F, Aziz MH and Ahmad N: Modulations of critical cell cycle regulatory events during chemoprevention of ultraviolet B-mediated responses by resveratrol in SKH-1 hairless mouse skin. Oncogene 23: 5151-5160, 2004.

36. Subramaniam G, Campsteijn C and Thompson EM: Co-expressed Cyclin D variants cooperate to regulate proliferation of germline nuclei in a syncytium. Cell Cycle 14: 2129-2141, 2015. International (CC BY-NC-ND 4.0) License. 